\title{
Pectoral Nerves I, II and Serratus Plane Blocks in Multimodal Analgesia for Mastectomy: A Randomised Clinical Trial
}

\author{
Hammad Nabeel Najeeb, Syed Raza Mehdi, Athar Mukhtar Siddiqui and Syeda Kiran Batool \\ Department of Anesthesia, Shaukat Khanum Memorial Cancer Hospital, Lahore, Pakistan
}

\begin{abstract}
Objective: To primarily assess pain score in first 24 hours in PECS (PECtoral Serratus) block group undergoing mastectomy; secondary objective was to observe opioid and antiemetic consumption in the postoperative period.

Study Design: Observer-blinded randomised control trial.

Place and Duration of Study: Department of Anesthesiology, Shaukat Khanum Memorial Cancer Hospital Lahore (SKMCH), from February to December 2017.

Methodology: One hundred and twenty patients of more than 18 years, ASA I and II, planned for unilateral elective modified radical mastectomy under general anesthesia, were scheduled randomly to receive either general anesthesia plus PECS block $(n=60)$ or general anesthesia alone $(n=60)$. Pain scores at fixed intervals were measured using Numeric Pain Rating Score (NPRS) after the surgery.

Results: Pain score in the PECS block group was significantly lower than the control group in postoperative period. Less dose of morphine was required in the PECS block group postoperatively for pain control. Postoperative nausea and vomiting (PONV) incidence was lower in the intervention group (PECS block) as compared with the control group.

Conclusion: PECS block has a better analgesic efficacy in patients undergoing mastectomy.
\end{abstract}

Key Words: Pectoral nerves I \& /l block, Serratus plane block, General anesthesia, Opioid analgesia, Breast cancer and modified radical mastectomy.

How to cite this article: Najeeb HN, Mehdi SR, Siddiqui AM, Batool SK. Pectoral nerves I, II and serratus plane blocks in multimodal analgesia for mastectomy: A randomised clinical trial. J Coll Physicians Surg Pak 2019; 29(10):910-4.

\section{INTRODUCTION}

The incidence rate of breast cancer in Pakistani females is among the highest in the region. ${ }^{1}$ According to $\mathrm{WHO}$, breast cancer rates are increasing drastically and young females are also being screened for cancer incidence. ${ }^{2}$ More than 1,000 breast surgeries are performed in $\mathrm{SKMCH}$ each year. 3 Literature shows that acute postoperative pain is a common problem faced after mastectomy. If acute pain is not well managed in the first 24 hours, it can potentially develop into chronic postmastectomy pain with impaired quality of life. ${ }^{4}$ Most anesthesiologists, as a part of good practice traditionally, use a multimodal analgesia technique for breast surgeries. These techniques include local anesthetic infiltration with NSAIDs, opioids and paracetamol. ${ }^{5}$

Regional anesthesia techniques have shown promising results in order to improve acute postoperative pain relief. 6 This has a benefit of reducing the dependence of opioid requirement for analgesia as a part of intraoperative and postoperative regimen. ${ }^{7}$

Correspondence to: Dr. Hammad Nabeel Najeeb, Department of Anesthesia, Shaukat Khanum Memorial Cancer Hospital,

Lahore, Pakistan

E-mail: hammadnabeel@skm.org.pk

Received: May 13, 2019; Revised: July 17, 2019;

Accepted: August 08, 2019
Thoracic paravertebral block (TPVB), thoracic epidural block (TEB), intercostal nerve block, inter-scalene block, and wound infiltration have all been used and described in literature as effective analgesic techniques. But these are invasive procedures and carry a risk of developing untoward complications, as these techniques require a learning curve. ${ }^{8}$ The pectoral nerve block is a relatively newer technique described by Blanco et al.9,10 In this technique, the local anaesthetic is deposited into an interfascial plane (PECS I) between the pectoralis major muscle and the pectoralis minor muscle where (PECS II block) is lateral to PECS I injection point, in between pectoralis minor and serratus anterior muscle to block intercostal nerves. Similarly in serratus anterior block, local anesthesia is infiltrated between serratus anterior and latissimus dorsi muscle at the level of third rib. ${ }^{11}$

These techniques were attempted to block the pectoral, inter-costo-brachial, intercostals $3^{\text {rd }}$ to $6^{\text {th }}$, and long thoracic nerves. Our study included serratus plane block along with the pectoral nerve I and II blocks described above. Use of these techniques, as part of a balanced anesthesia, can help in preventing central sensitisation and also decrease opioid dependent complications.

The primary objective of this trial was to observe the pain score in first 24 hours in PECS block group and control group in patients undergoing simple mastectomy or modified radical mastectomy (MRM) surgery. The 
secondary objective was to observe opioid and antiemetic consumption postoperatively in these two groups.

\section{METHODOLOGY}

After obtaining approval from Institutional Review Board of Shaukat Khanum Memorial Cancer Hospital (SKMCH) Lahore, Pakistan. This prospective (observer-blinded) randomised clinical trial was conducted from February to December 2017. Females, ASA I and II adult patients more than 18 years of age, scheduled to undergo elective unilateral MRM under general anesthesia, were selected. Altman's nomogram was used for simple size measurement. We assumed $\alpha$ to be 0.05 and kept the power of the study at 0.80 , sample size of 100 patients was calculated. To compensate the dropouts, we enrolled 120 patients.

Exclusion criteria was patient refusal, history of allergy to bupivacaine, contraindications to regional anesthesia (coagulopathy and local infection), BMl $>40 \mathrm{Kg} / \mathrm{m}^{2}$, bilateral mastectomy, use of chronic pain medications, illicit drugs or alcohol abuse and psychiatric problems.

Informed written consent was obtained. Patients were then randomly assigned to one of the 2 groups using a predetermined random 1:1 sequence. Group A (PECS block group) received pectoral nerve I, II and serratus plane block and general anesthesia $(n=60)$ and Group B (Control group) received general anesthesia alone $(n=60)$ along with standard perioperative analgesia which included paracetamol $(1 \mathrm{gm})$, non-steroidal anti-inflammatory medication (diclofenac $75 \mathrm{mgs}$ ) and morphine (variable dose) intravenously. Both groups received a standardised preoperative care. All the recruited patients were given a chart of numeric pain scoring system (NPRS) one-day prior to surgery and they were taught how to mark the pain score.

All standard monitorings were attached to the patients in both groups. Pre-induction vitals were noted and general anesthesia was induced with fentanyl $1 \mathrm{mcg} / \mathrm{kg}$, propofol $2 \mathrm{mg} / \mathrm{kg}$, atracurium $0.5 \mathrm{mg} / \mathrm{kg}$ and supraglottic airway device (Laryngeal mask airway) was placed with confirmation of end tidal $\mathrm{CO}_{2}$ on capnography. Inhalational anesthesia was maintained at 1 MAC of sevoflurane with $100 \%$ oxygen due to non-availability of air in the hospital during the study period.

After the induction of general anesthesia, PECS block was administered in the Group A patients via ultrasoundguided technique. We used Mindray M7 portable ultrasound system using linear probe with $(5-10 \mathrm{MHz})$ frequency. After cleaning the infra-clavicular and axillary region with $2 \%$ chlorhexidine in $70 \%$ alcohol solution, ultrasound probe was placed in the infra-claviclar region and pectoral major and minor were identified. After identification of the landmarks 20 gauge $50 \mathrm{~mm}$ visoplex needle was inserted in plane direction. $20 \mathrm{ml}$ of $0.25 \%$ bupivacaine (within the safe limit of its dose) was infiltrated between pectoralis major and pectoralis minor muscle and the spread was visualised on the ultrasound screen.

In serratus plane block, ultrasound probe was placed over the mid-axillary region of the thoracic cage in a sagittal plane. Ribs were identified inferiorly and laterally, until the identification of the 3 rd rib in the mid axillary line. $20 \mathrm{ml}$ of $0.25 \%$ bupivacaine was injected in between Serratus anterior muscle and latissimus dorsi muscle. No intervention was done in the control group.

Only two anesthesia consultants performed the PECS blocks, as described above, and all the details were documented on anesthesia intra-op assessment sheet.

Surgery was commenced 20 mins after the block. Blood pressure and heart rate readings were closely analysed and a supplemental analgesia of $1.5 \mathrm{mg}$ morphine was given intraoperatively in incremental doses, if the heart rate and blood pressure exceeded more than $20 \%$ of the baseline readings.

At the end of the surgery, paracetamol $1 \mathrm{~g} / 100 \mathrm{~mL} \mathrm{IV}$ infusion was administered over 10 mins and sevoflurane was switched off. A prophylactic dose of $4 \mathrm{mg}$ ondansetron was given and neostigmine/glycopyrolate $2.5 / 0.2 \mathrm{mg}$ was administered intravenously for neuro-muscular blockade reversal. After responding to verbal command, patient's supraglottic airway was removed and patient was shifted to PACU.

After shifting the patient to PACU, all standard monitoring were applied to the patient again. Registered pain nurses, who were blinded with the patient grouping, assessed the postoperative pain using NPRS at the time of arrival at PACU ( 0 minute) and then at 30 minutes after surgery and at discharge from PACU. Pain score was further assessed at the surgical floor at 6 hours, 12 hours and 24 hours post-surgery by the ward nurses who were trained in pain assessment and NPRS. If the NPRS scores was greater than $3 / 10$, rescue analgesic dose of $1.5 \mathrm{mg}$ of morphine was administered slowly through the intravenous route and the pain score was reassessed after 15 minutes. If it was still more than 3 , additional dose of $1.5 \mathrm{mg}$ morphine was repeated. This cycle continued till pain resolved.

The incidence of PONV was assessed in PACU using a 5 -point scale (4-0), where 4 was rated as vomiting more than once, 3 was rated as one episode of vomiting, 2 was rated as severe nausea, 1 was rated as mild nausea, and 0 being no nausea. If the PONV score was more than 2, ondansetron $2 \mathrm{mg} \mathrm{IV}$ was administered. Patients were discharged to the surgical floor once they reached a score of 9/10 on the modified Aldrete scoring system. Quantitative variables like age, weight, sex, were presented in the form of mean \pm S.D and percentages. For nominal data, statistical analysis was performed by means of Chi-square test. Comparison of pain scores 
was considered significant if there was at least 1 point of difference on the NPRS scale in both groups. The data that followed a normal distribution pattern were analysed using t-test for equality of means. $\mathrm{P}<0.05$ was set as the cutoff point for significance. Statistical analyses were performed using SPSS version 23.0 (SPSS Inc, Chicago, Illinois).

\section{RESULTS}

A total of 120 patients completed the study with 60 patients in each group. Overall mean age was 47.42 \pm 11.43 years in PECS block group and $45.28 \pm 10.81$ years in control group. Demographic variables such as age, weight and body mass index (BMI) of statistical significance is shown in Table $\mathrm{I}$.

Out of 60 patients in the PECS block group, 44 patients (73.3\%) underwent mastectomy and 16 patients (26.6\%) underwent mastectomy with axillary lymph node dissection. In the control group, 34 patients $(56.6 \%)$ underwent simple mastectomy and 26 patients $(43.3 \%)$ underwent mastectomy with axillary lymph node dissection.

Only 33 patients $(45 \%)$ required additional opioids intraoperatively in the PECS block group; while in the control group, 43 patients $(71 \%)$ required additional dose of morphine. For those patients requiring intraoperative opioids, the cumulative dose of additional morphine administered in the PECS block group was $147 \mathrm{mg}$ as compared to $247.5 \mathrm{mg}$ in the control group. Mean opioid consumption was $2.6 \pm 1.84 \mathrm{mg}$ in the PECS block group, compared to $5.36 \pm 1.98 \mathrm{mg}$ in control group with the $p$-value of 0.009 .

Twenty-three (38.3\%) patients required postoperative morphine the PECS block group, whereas 26 (43.3\%) patients required postoperative morphine in the control

Table I: Demographics of patient undergoing mastectomy.

\begin{tabular}{l|c|c}
\hline Demographic variables & PECS block $(\mathrm{n}=60)$ & Control group $(\mathrm{n}=60)$ \\
\hline Age (years) & $47.42 \pm 11.43$ & $45.28 \pm 10.81$ \\
Weight $(\mathrm{kg})$ & $76 \pm 9.3$ & $69 \pm 6.4$ \\
BMI $\left(\mathrm{kg} / \mathrm{m}^{2}\right)$ & 28.7 & 24.5 \\
Duration of surgery (minutes) & $138 \pm 41$ & $146 \pm 27$ \\
\hline
\end{tabular}

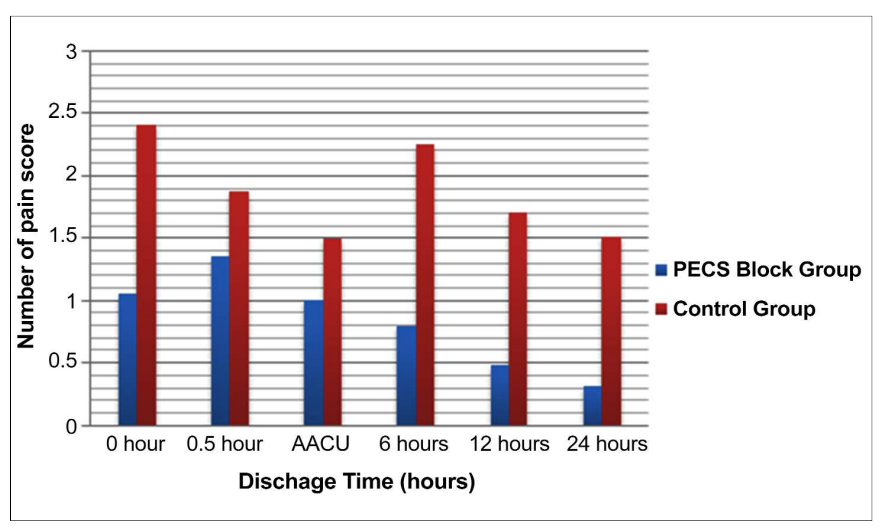

Figure 1: Comparison of NPRS score between the two groups at fixed time intervals.
Table II: Indicating mean pain score with (standard deviation) and $\mathrm{p}$-values at different time intervals.

\begin{tabular}{l|c|c|c}
\hline Time variable & $\begin{array}{c}\text { Pain score in } \\
\text { PECS block }\end{array}$ & $\begin{array}{c}\text { Pain score in } \\
\text { control group }\end{array}$ & -value \\
\hline $0 \mathrm{Hr}$ & $1.05(1.63)$ & $2.42(2.17)$ & $<0.001$ \\
\hline $0.5 \mathrm{Hr}$ & $1.35(1.23)$ & $1.90(1.38)$ & 0.002 \\
\hline PACU discharge time & $1.0(0.84)$ & $1.50(0.98)$ & 0.003 \\
\hline $6 \mathrm{Hrs}$ & $0.8(1.23)$ & $2.25(1.90)$ & $<0.001$ \\
\hline $12 \mathrm{Hrs}$ & $0.48(0.72)$ & $1.70(2.02)$ & $<0.001$ \\
\hline $24 \mathrm{Hrs}$ & $0.32(0.87)$ & $1.52(1.85)$ & $<0.001$ \\
\hline
\end{tabular}

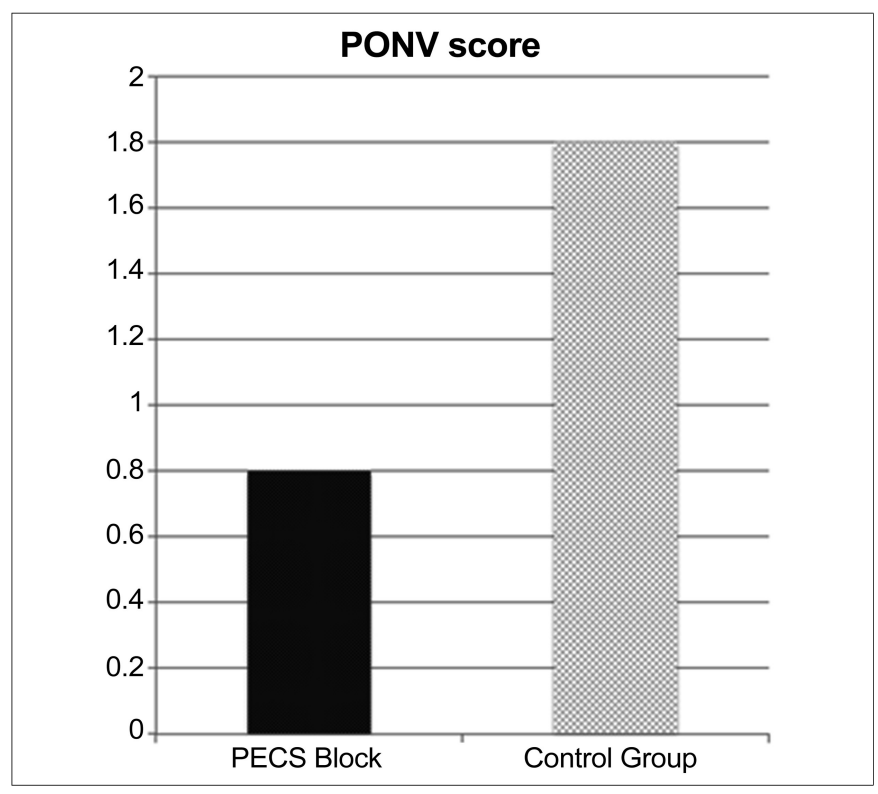

Figure 2: Comparison of PONV scores in postoperative period.

group. Postoperative morphine consumption to keep the pain scores less than 3 was somewhat equal in both groups with the values of $2.60 \pm 0.59 \mathrm{mg}$ and $2.67 \pm 0.63$ $\mathrm{mg}$ in the PECS and control groups, respectively $(p=$ 1.0). Numeric pain rating scores in the PECS block group and control group are represented in the Table II and Figure 1.

Mean PACU discharge time in the PECS block group was $92.75 \pm 27.37$ mins and $130 \pm 50.78$ mins in the control group with p-value $<0.001$.

Cumulative postoperative antiemetic (ondansetron) consumption in the PECS group was $61.5 \mathrm{mg}$ as compared to $90 \mathrm{mg}$ in the control group. Mean antiemetic consumption was $1.02 \pm 0.3 \mathrm{mg}$ in the PECS block group, compared to $1.5 \pm 0.18 \mathrm{mg}$ in control group. Comparison of postoperative nausea vomiting score is shown in Figure 2. Mean PONV score in PECS block group was $0.8 \pm 0.9$ and in the control group was $1.8 \pm 1.22, p<0.01$.

\section{DISCUSSION}

Regional anesthesia techniques are acclaiming popularity as more regional blocks are used to compliment general anesthesia for improved patient satisfaction. 12 It has 
conventionally been used for obstetrics and orthopedic surgeries in our country, 13,14 but the role of regional block for breast cancer surgery has yet to be established. Previous studies done on PECS block used different local anesthesia drugs to assess the time of pain-free period. 15 However, these studies were only limited to either pectoral nerve I, II block or paravertebral blocks. Our study included serratus plane block in addition to the pectoral nerve blocks. Serratus anterior block anesthetise the lateral cutaneous branches of thoracic intercostal, thoracodorsal and thoracic longus nerves. This provides analgesia in the antero-lateral wall of the thorax.16,17 There is no gold standard block technique for the breast cancer surgery, however many authors strongly advocate the use of paravertebral block (PVB) as the technique of choice for relief of pain after breast surgery. 18 Unfortunately, PVB does not block medial and lateral pectoral nerves as well as long thoracic and thoracodorsal nerves. Therefore, it spares the analgesia of the region in surgeries involving axillary dissection. ${ }^{19,20}$ Secondly, PVB is more invasive technique as compared to PECS block. It is more prone to serious complications that include transforming into epidural block or even total spinal anesthesia, whereas these complications have not yet been reported with PECS block technique. A Swedish study reported that the complications which occurred after performing PVB in 367 patients, included hypotension (4.6\%); vascular puncture $(3.8 \%)$; pleural-puncture $(1.1 \%)$; and pneumothorax $(0.5 \%) .21$ PECS block is a less invasive technique and; hence, it is devoid of these complications.

This prospective randomised study shows that PECS block performed in patients after the induction of anesthesia, resulted in less pain score in the first 24 hours after surgery. Intraoperative morphine requirement was lower in the PECS block group as observed in the results. Postoperative morphine dose was almost equal in both groups but the fewer patients in PECS block required postoperative morphine than the control group. This deduction also supplicated a lower PONV score leading to less consumption of ondansetron in the PECS block group in the postoperative period.

Pain at PACU discharge time was somewhat equal in both groups. This (PACU discharge time) was variable and patients in PECS block achieved modified Aldrete score of $\geq 9 / 10$ earlier than the patient in the control group. Hence, mean PACU discharge time was lower in PECS block group.

This study has a few limitations. Firstly, the level of the block could not be assessed after its infiltration as it was performed under general anesthesia. Many of these patient population hails from a conservative background where exposing females is not considered modest; hence, the patients were not comfortable for an awake block. Secondly, there was a language barrier in some.
Communication is a vital part of pain score assessment, hence the assessing nurse may have underrated the pain score due to this barrier.

More prospective studies should be carried out to compare the analgesic efficacy of PECS blocks with other regional blocks such as paravertebral, erector spine and neuraxial blocks for mastectomy

\section{CONCLUSION}

The pectoral nerve I, II + serratus plane (PECS) blocks produce better quality analgesia when combined with general anesthesia for breast surgery. It is a simple yet effective method of managing postoperative pain after surgery. The authors recommend the use of ultrasound for the use of this block technique, as our population did not develop any complications after the infiltration of block. Visualisation of the spread of the block is also an effective way to confirm the spread of the block in the right plane.

\section{ETHICAL APPROVAL:}

This prospective (observer-blinded) randomised clinical trial was conducted after obtaining approval from Institutional Review Board of Shaukat Khanum Memorial Cancer Hospital (SKMCH) Lahore, Pakistan.

\section{PATIENTS' CONSENT:}

Informed written consent was obtained from patients.

\section{CONFLICT OF INTEREST:}

Authors declared no conflict of interest.

\section{AUTHORS' CONTRIBUTION:}

HNN: Data collection, drafting, analysis and interpretation of data and manuscript writing.

SRM: Initial design of the study, supervised the study and PECS block infiltration in study patients.

AMS: Literature search, proofreading of the manuscript and PECS block infiltration in the study patients.

SKB: Contributed to initial concept design of the study.

\section{REFERENCES}

1. Bhurgri Y, Bhurgri A, Nishter S, Ahmed A, Usman A, Pervez S, et al. Pakistan - Country profile of cancer and cancer control 1995-2004. J Pak Med Assoc 2006; 56:124-30.

2. Ferlay J, Soerjomataram I, Dikshit R, Eser S, Mathers C, Rebelo $\mathrm{M}$, et al. Cancer incidence and mortality worldwide: Sources, methods and major patterns in GLOBOCAN 2012. Int J Cancer 2015; 136:E359-86.

3. HIS system data. Shaukat Khanum Hospital and Research Centre Lahore.

4. Andersen KG, Duriaud HM, Jensen HE, Kroman N, Kehlet H. Predictive factors for the development of persistent pain after breast cancer surgery. Pain 2015; 156:2413-22.

5. Afonso AM, Newman MI, Seeley N, Hutchins J, Smith KL, Mena G, et al. Multimodal analgesia in breast surgical 
procedures: Technical and pharmacological considerations for liposomal bupivacaine use. Plast Reconstr Surg Glob Open 2017; 5:e1480.

6. Richebé P, Rivat C, Liu SS. Perioperative or postoperative nerve block for preventive analgesia: Should we care about the timing of our regional anesthesia? Anesth Analg 2013; 116: 969-70.

7. Gürkan Y, Aksu C, Kus A, Yörükoglu UH. Ultrasound-guided erector spinae plane block reduces postoperative opioid consumption following breast surgery: A randomized controlled study. J Clin Anesth 2018; 50:65-8.

8. Syal K, Chandel A. Comparison of the post-operative analgesic effect of paravertebral block, pectoral nerve block and local infiltration in patients undergoing modified radical mastectomy: A randomised double-blind trial. Indian J Anaesth 2017; 61:643-8.

9. Blanco R. The "PECS block": A novel technique for providing analgesia after breast surgery. Anaesthesia 2011; 66:847-8.

10. Blanco R, Fajardo M, Parras Maldonado T. Ultrasound description of PECS II (modified Pecs I): A novel approach to breast surgery. Rev Esp Anestesiol Reanim 2012; 59:470-5.

11. Porzionato A, Macchi V, Stecco C, Loukas M, Tubbs RS, De Caro R. Surgical anatomy of the pectoral nerves and the pectoral musculature. Clin Anat 2012; 25:559-75.

12. Ullah H, Samad K, Khan FA. Continuous interscalene brachial plexus block versus parenteral analgesia for postoperative pain relief after major shoulder surgery. Cochrane Database Syst Rev 2014; 2:CD007080.

13. Akram M, Farooqi FM, Irshad M, Faraz UI Hassan S, Awais SM. Role of addition of dexamethasone and ketorolac to lignocaine intravenous regional anesthesia (Bier's Block) to improve tourniquet tolerance and post-operative analgesia in hand and forearm surgery. J Pak Med Assoc 2015; 65 (11 Suppl 3): S128-31.

14. Shah AA, Rasool A, Alam MA, Naseem Y, Rasool M, Hussain A, et al. Efficacy of phenylephrine infusion verses colloid preloading in resolving hypotension due to spinal anaesthesia during caesarean section. J Ayub Med Coll Abbottabad 2018; 30:377-80.

15. Thomas M, Philip FA, Mathew AP, Jagathnath Krishna KM. Intraoperative pectoral nerve block $(\mathrm{Pec})$ for breast cancer surgery: A randomized controlled trial. J Anaesthesiol Clin Pharmacol 2018; 34:318-23.

16. Madabushi R, Tewari S, Gautam SK, Agarwal A, Agarwal A. Serratus anterior plane block: A new analgesic technique for post-thoracotomy pain. Pain Physician 2015; 18:E421-4.

17. Tighe SQ, Karmakar MK. Serratus plane block: Do we need to learn another technique for thoracic wall blockade? Anaesthesia 2013; 68:1103-6.

18. Naja MZ, Ziade MF, Lonnqvist PA. Nerve-stimulator guided paravertebral blockade vs. general anaesthesia for breast surgery: A prospective randomized trial. Eur J Anaesth 2003; 20:897-903.

19. Terheggen MA, Wille F, Borel Rinkes IH, lonescu TI, Knape JT. Paravertebral blockade for minor breast surgery. Anesth Analg 2002; 9:355-9.

20. Coveney E, Weltz CR, Greengrass R, Iglehart JD, Leight GS, Steele SM, et al. Use of paravertebral block anesthesia in the surgical management of breast cancer: Experience in 156 cases. Ann Surg 1998; 227:496-501.

21. Lönnqvist PA, MacKenzie J, Soni AK, Conacher ID. Paravertebral blockade. Failure rate and complications. Anaesthesia 1995; 50:813-5.

.......... 